\title{
Sentuhan Digital Bisnis (Teknologi Informasi) pada UMKM Studi Kasus : Pemasaran Produk Adi Upakara
}

\section{Nyoman Tri Anindia Putra ${ }^{1 *}$, Ketut Sepdyana Kartini ${ }^{2}$, Luh Gede Kusuma Dewi ${ }^{3}$}

1,2 Jurusan Teknik Informatika STMIK STIKOM Indonesia

${ }^{3}$ Jurusan Ekonomi dan Akuntansi, Universitas Pendidikan Ganesha

\author{
A R T I C L E I N F O \\ Article history: \\ Received 19 April 2019 \\ Received in revised form \\ 10 May 2019 \\ Accepted 12 June 2019 \\ Available online 25 July \\ 2019 \\ Kata Kunci: \\ Sosial Media, Digital Bisnis, \\ PKM, Sistem Informasi \\ Keywords: \\ Social Media, Digital \\ Business, PKM, Information \\ Systems
}

\begin{abstract}
A B S T R A K
Pelaksanaan upacara dalam Agama Hindu tidak lepas dari upakara/banten. Di Banjar Pondok Kelod, Desa Gadungan Kecamatan Selemadeg Timur terdapat kelompok Usaha Kecil Menengah (UKM) yang bergerak di bidang pembuatan banten. Usaha yang dijalani sejak tahun 2010 hanya menggunakan sistem pre order (membuat bila ada pesanan). Berdasarkan hasil wawancara permasalah yang di alami mitra adalah pemasaran produk masih sangat terbatas. Tujuan dari Pengabdian Kepada Masyarakat ini adalah untuk meningkatkan pemahaman dan keterampilan mitra dalam bentuk, teknik pemasaran dengan sentuhan Digital Bisnis serta menyempurnakan pengetahuan mitra tentang pemanfaatan Teknologi Informasi yang digunakan untuk membantu UKM dalam memasarkan produk. Adapun kegiatan mulai dari pelatihan pengambilan gambar menggunakan smartphone sampai pada proses unggah ke dalam sosial media telah berjalan dengan baik dan menghasilkan luaran berupa Akun Sosial media (Facebook dan Instagram) serta memperkenalkan website telah berhasil dibuat dan dioperasikan untuk umkm.
\end{abstract}

\section{A B S T R A C T}

The implementation of ceremonies in Hinduism is inseparable from upakara / banten. In Banjar Pondok Kelod, Desa Gadungan Kecamatan Selemadeg Timur there is a group of Small and Medium Enterprises (UKM) which is engaged in making offerings. The business that has been undertaken since 2010 only uses a pre-order system. Based on the results of interviews the problems experienced by partners is that marketing products is still very limited. The aim of this Community Service is to improve partners 'understanding and skills in the form of, marketing techniques with a touch of Digital Business and perfect partners' knowledge about the use of Information Technology that is used to assist SMEs in marketing products. The activities ranging from training in taking pictures using a Smartphone to the process of uploading to social media have been going well and resulted in outcomes in the form of social media accounts (Facebook and Instagram) and introducing a website that has been successfully created and operated for umkm.

\footnotetext{
* Corresponding author.

E-mail addresses: nymntrianin@email.com (I Nyoman Tri Anindia Putra)
} 


\section{Pendahuluan}

Sentuhan Digital bisnis saat ini sudah semakin marak dilakukan, tentunya hal ini dibuktikan dengan beralihnya era yang sudah memasuki industry 4.0 yang mana sudah masuk sampai keranah UMKM. bisnis menerapkan teknologi dan media digital untuk meningkatkan daya saing UMKM mereka melalui optimalisasi proses internal dengan memanfaatkan media online sebagai kuncinya . Kunci proses digital bisnis adalah mencakup penelitian dan pengembangan, pemasaran, manufaktur, dan logistik masuk dan keluar. Digital bisnis sangat diperlukan guna meningkatkan banyak sector mulai dari micro hingga macro. Tidak luput dari hal tersebut bidang kearifan local pun harus ikut dilestarikan guna menjaga kearifan local tetap eksis dan terjaga diperlukan sentuhan digital bisnis agar UMKM yang bersifat kearifan local tidak termarginalkan.

Pelaksanaan upacara dalam Agama Hindu tidak lepas dari upakara/banten. Bebantenan di Bali memiliki ciri khas yang unik dan sangat beraneka ragam. Selain itu, bebantenan juga mengandung budaya seni dan adat, yang berciri Desa-Kala-Patra serta Nista-Madya-Utama daerah setempat (Utari, 2007). Bentuk banten di masing-masing daerah ada yang sama namun ada pula yang berbeda. Hal ini menyesuaikan dengan budaya daerah setempat dan tingkat kesenian yang ada pada daerah yang bersangkutan akan tetapi, maksud dan makna dari Banten tersebut tetaplah sama.

Menurut Wijayanandha (2003), upakara-upakara yadnya mempunyai tujuan yang satu yaitu menghaturkan bhakti suci dengan perwujudan berupa sarana. Upakara/ banten adalah perwujudan/tapakan dari Hyang Widhi. Dalam banten di bali, pembuatannya memakai bahan yang melambangkan dewa-dewa tertentu, misalnya kelapa wujud Api Dewa Brahma, air wujud Dewa Wisnu dan lain-lain.

Kini, masyarakat bali lebih memilih membeli banten untuk kegiatan upacara keagamaan karena untuk membuat banten banyak umat memang tidak tahu banten apa saja yang diperlukan untuk suatu upacara. Hal ini disebabkan karena bebantenan yang digunakan dalam suatu upacara tersebut seringkali kompleks sehingga cenderung sulit dipahami oleh masyarakat luas secara umum. menyusul kesibukan masyarakat Hindu di Bali. Banyak perempuan Bali yang dulu menjadi pemegang peran dalam membuat sarana upacara di rumah, kini harus bekerja. Sehingga kini menjalani ritual upacara dengan kepraktisan sudah jadi tren yang berkembang di masyarakat (Darmayana, 2011).

Di Banjar Pondok Kelod, Desa Gadungan Kecamatan Selemadeg Timur terdapat kelompok Usaha Kecil Menengah (UKM) yang bergerak di bidang pembuatan banten. Mitra dalam kegitan ini adalah ibu Ni Wayan Renten sebagai pemiliki UKM. Sebelum menekuni usaha ini mitra adalah seorang petani. Selain sebagai petani, mitra juga memiliki keahlian membuat banten yang kemudian di jual. Keahlian ini dijadikan modal utama untuk membuat usaha bersama anggota. Usaha yang dijalani sejak tahun 2010 hanya menggunakan sistem pre order (membuat bila ada pesanan). Produksi banten dilakukan oleh mitra tersebut masih musiman, dalam arti masih dipengaruhi oleh hari baik dalam menentukan upacara keagamaan serta hari raya Agama Hindu yang telah disesuaikan dengan kalender Bali. Jadi jika dalam beberapa bulan jumlah hari raya di Bali tidak terlalu banyak, maka produksi banten menurun bahkan tidak melakukan produksi. Permasalah utama yang di alami mitra berdasarkan hasil wawancara yaitu proses pemasaran produk usaha ini masih sangat tradisional dimana dari sisi pemasaran produk, saat ini masih sebatas di lingkungan desa dan proses penjualan masih berdasarkan informasi teman ke teman (mulut ke mulut) dan mitra belum tahu cara mencari pelanggan di luar desa ataupun di sosial media. Dampak yang terjadi adalah permintaan akan produk banten tidak bertambah. pemasaran secara online belum pernah dilakukan. Metode pemasaran online dapat memperluas pangsa pasar. Ibu Ni Wayan Renten juga mengakui bahwa beliau ingin melakukan promosi secara online, namun karena keterbatasan pengetahuan tentang internet, media sosial, dan website metode tersebut belum dilakukan. Sehingga berdasarkan permasalahan tersebut penulis melakukan pengabdian kepada masyarakat melalui pelatihan Digital Bisnis dengan sentuhan teknologi informasi bagi mitra UKM Adi Upakara yang bertujuan untuk meningkatkan pengetahuan terkait pemasaran produk secara online melalui internet, sosial media, website, serta tata cara penggunaannya.

\section{Metode}

Sebuah pencapaian target memerlukan metode yang berkaitan dengan tujuan, luaran dan dampak. Beberapa tujuan utama dari kegiatan ini adalah peningkatan kesejahteraan masyarakat, pelestarian budaya dan pengembangan kemampuan, maka metode yang diterapkan dalam pelaksanaan PKM sesuai dimulai dari analisis kebutuhan mitra, pelaksanaan aktivitas pengabdian kepada masyarakat melalui program PKM, serta evaluasi yang merupakan program pemantauan untuk melihat sejauh mana tingkat pengetahuan mitra dalam pelatihan yang telah dilakukan melalui kuesioner. 
Tabel 1. Materi Pemasaran Dengan Pemanfaatan Teknologi Informasi

\begin{tabular}{|c|c|c|}
\hline No & Kompetensi Dasar & Materi Pokok \\
\hline \multirow{5}{*}{1} & Mitra mampu membuat konten & Praktek pengambilan gambar dengan kamera \\
\hline & promosi & 2. Dasar-dasar penyusunan kalimat promosi \\
\hline & & 1. Pengenalan internet dan Digital Bisnis \\
\hline & & 2. Praktek pembuatan e-mail \\
\hline & & 3. Dasar-dasar Sistem Informasi \\
\hline \multirow{3}{*}{2.} & Mampu memahami konsep $e$ - & 4. Cara upload Produk ke sistem Website. \\
\hline & commerce & $\begin{array}{l}\text { 5. Bagaimana menangani order yang masuk pada sistem } \\
\text { Website }\end{array}$ \\
\hline & & $\begin{array}{l}\text { 6. Bagaimana mengetahui laporan penjualan dari sistem } \\
\text { Website }\end{array}$ \\
\hline \multirow{2}{*}{3.} & Mampu menggunakan media & 1. Praktek menggunakan Facebook \\
\hline & sosial untuk promosi. & 2. Praktek menggunakan Instagram \\
\hline
\end{tabular}

\section{Hasil dan Pembahasan}

Tahap pertama dilakukan analisis kebutuhan mitra, yang mana mitra memiliki masalah terkait pemasaran produk usaha selama ini masih sangat tradisional. Untuk mengatasi masalah tersebut ketua pengusul berserta anggota memberikan pelatihan pemasaran dengan pemanfaatan teknologi informasi. Kegiatan ini menghadirkan narasumber yaitu Bapak I Nyoman Alit Arsana, M.T yang merupakan salah satu dosen Teknik Informatika di kampus STMIK STIKOM Indonesia. Adapun materi yang akan disampaikan diantaranya pelatihan pembuatan email, pemanfaatan sosial media seperti facebook, dan instagram dalam memasarkan produk serta pembuatannya, teknik pengambilan gambar dan proses upload ke sosial media baik itu facebook dan instagram, serta perkenalan website e-commerce. Kegiatan pelatihan berjalan dengan baik dan lancar, dimana anggota mitra sangat antusias dalam mendengarkan pemaparan dari narasumber yang diselingi dengan diskusi antara narasumber dengan anggota mitra UKM dalam membahas pelatihan tersebut. Berikut merupakan luaran dari pelatihan yang telah dilakukan dan dapat dilihat pada Gambar 1,2,3,4,dan 5.

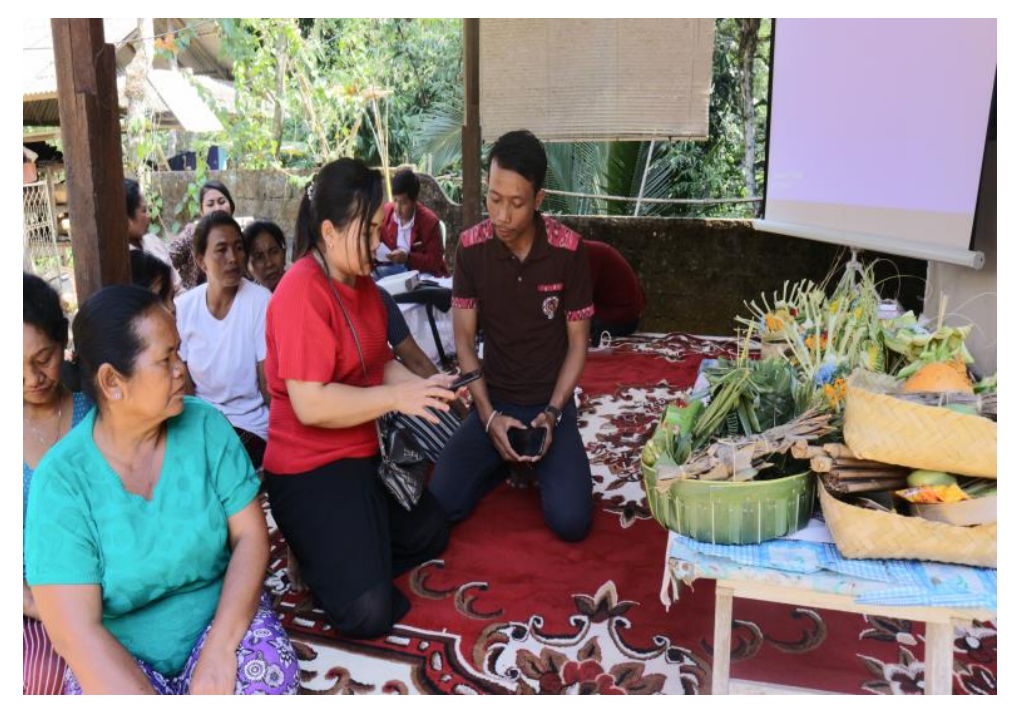

Gambar 1 kegiatan pelatihan pemanfaatan teknologi informasi 

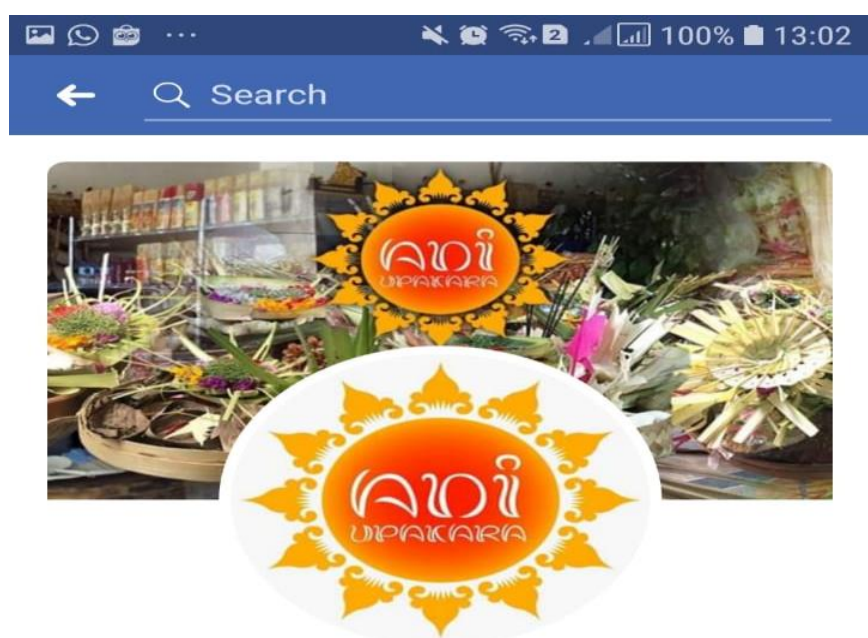

\section{Adi Upakara}

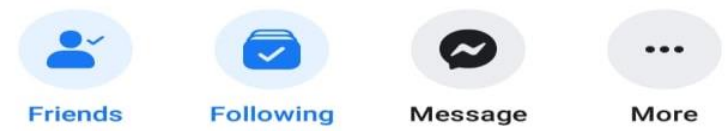

\section{... See Adi's About info}

Gambar 2. Hasil Luaran Sosial Media Facebook

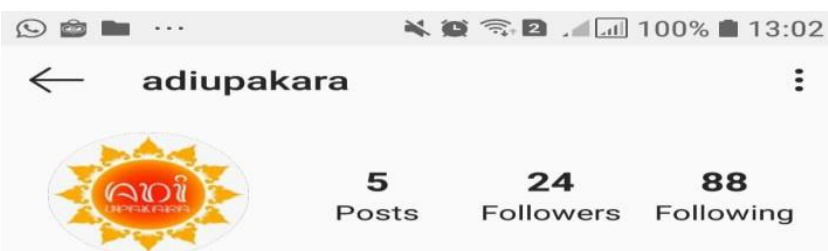

Adi Upakara

Menjual berbagai macam upakara

See Translation

www.adiupakara.com/

Followed by wsbinawati

Following $\sim$ Message $>$

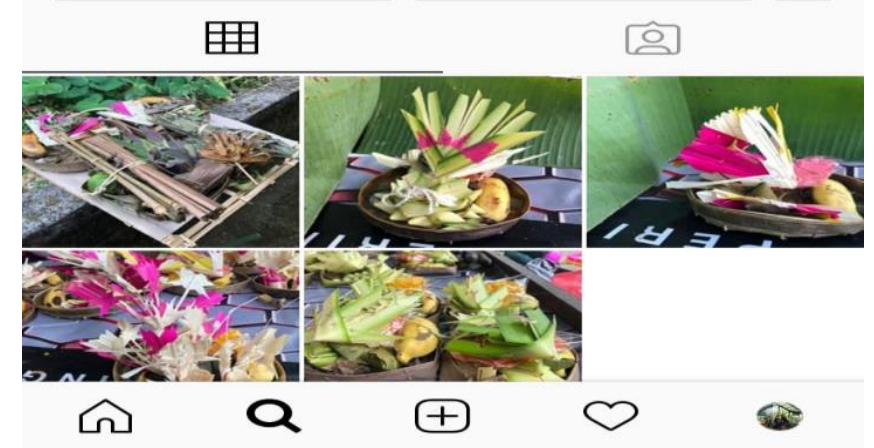

Gambar 3. Hasil Luaran Sosial Media Instagram. 

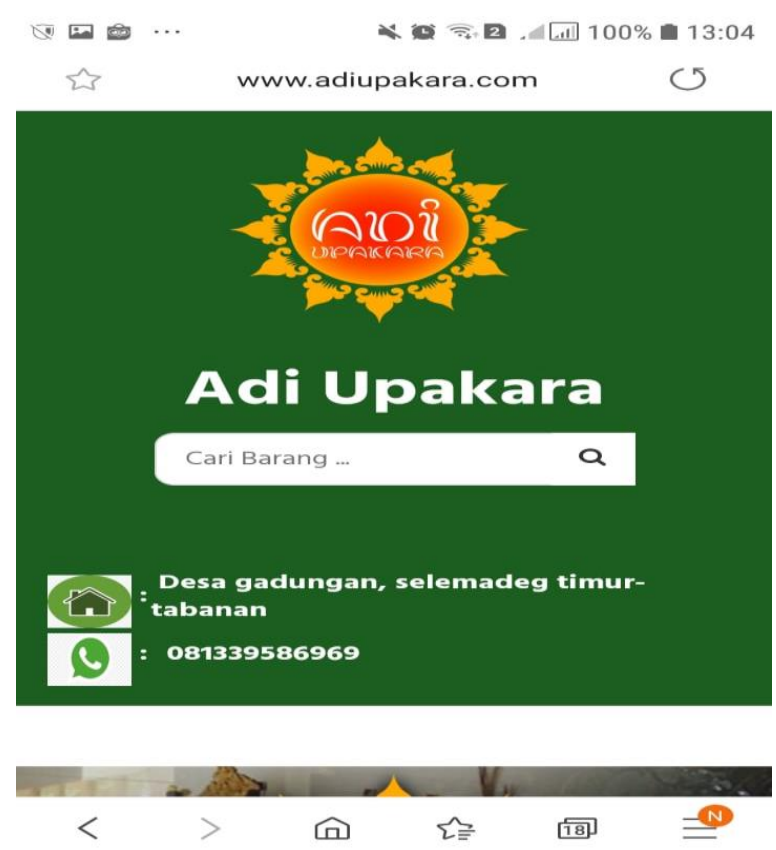

Gambar 4. Hasil Luaran website mitra

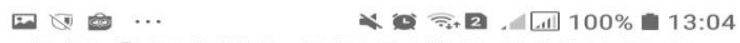

\section{PRODUK ADI UPAKARA}

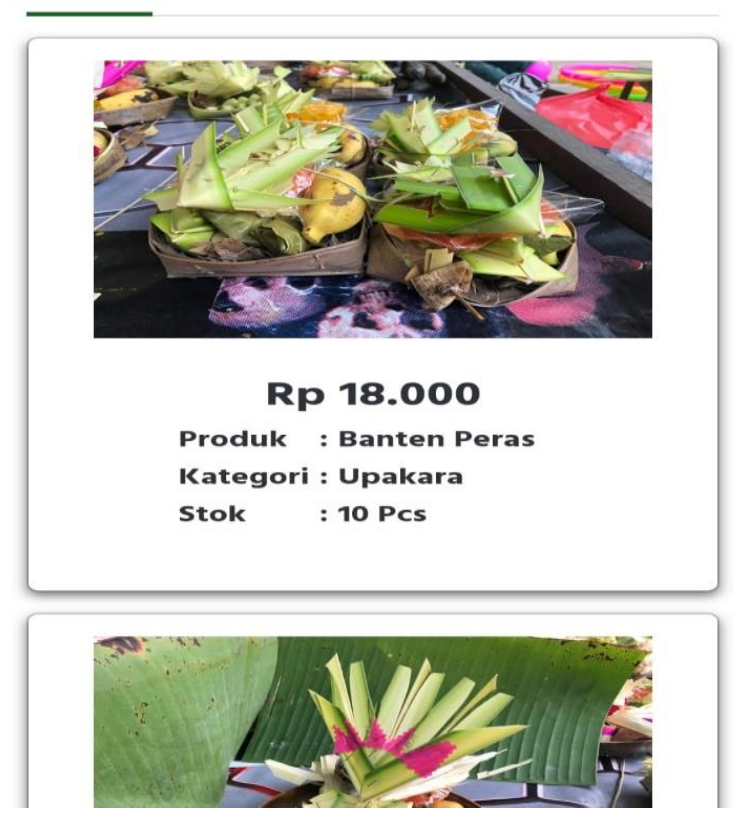

Gambar 5. Hasil pengambilan foto oleh mitra yang telah di upload.

Setelah proses pelatihan tentunya dilakukan evaluasi secara berkala serta pemantauan kegiatan mitra, adapun bentuk evaluasi yang menjadi tolak ukur kesuksesan proses pengabdian, yaitu 1 bulan setelah pelatihan mitra dapat mengelola media pemasaran berbasis website dan sosial media.

Adapun keunggulan dari luaran yang telah dicapai yaitu pemasaran secara online mampu memasarkan produk mitra lebih luas karena dapat di akses dimana saja, kapan saja dan oleh siapapun melalui sosial media dan website. Sedangkan kelemahannya jika diliat dari lokasi mitra kecepatan internet masih belum secepat internet yang ada di kota.

Tingkat kesulitan yang dialami oleh mitra terletak pada pemahaman penggunaan website hal ini dikarenakan mitra tidak pernah mengakses suatu website sehingga dilakukan pendampingan penggunaan website dari segi upload foto dan pemasangan harga pada website. 


\section{Simpulan dan Saran}

Berdasarkan hasil dari Sentuhan Digital Bisnis teknologi informasi yang digunakan untuk membantu mitra PKM dalam memasarkan produk mulai dari pelatihan pengambilan gambar menggunakan smartphone sampai pada proses unggah ke dalam sosial media telah berjalan dengan baik dan menghasilkan luaran berupa Akun Sosial media (Facebook dan Instagram) serta memperkenalkan website mitra UKM yang dapat membantu mitra dalam memasarkan produk mitra secara online.

\section{Daftar Rujukan}

Damayana, I.W. 2011. Menyama Braya. Studi Perubahan Masyarakat Bali. Fakultas Teologi, Universitas Kristen Satya Wacana

Utari Dewi, Ida Ayu. 2007. Pemodelan Sistem Bebantenan ditinjau dari Jenis-jenis Banten dan Perlengkapannya. Skripsi Teknik Elektro UNUD,Bali.

Wijayanandha, Mpu Jaya. 2003. Tetandingan Lan Sorohan Bebanten. Denpasar: Paramita. 